\title{
Investigation of Fusarium verticillioides on the Basis of RAPD Analysis, and Vegetative Compatibility in Iran
}

\author{
Zeynab Bahmani ${ }^{1 *}$, Reza Farokhi Nejad ${ }^{1}$, Khoshnood Nourollahi $^{2}$, Fatemeh Fayazi ${ }^{1}$ and Vida Mahinpo ${ }^{1}$ \\ ${ }^{1}$ Department of Plant Pathology, Shahid Chamran University of Ahwaz, Iran \\ ${ }^{2}$ Department of Plant Protection, Collage of Agriculture, Ilam University, Iran
}

\begin{abstract}
Genetic diversity among 41 isolates was determined using vegetative compatibility groups from different regions of Fars (Firozabad, Ramjerd, Drodzan, Shiraz, Pasargad, Sepidan and Mravdasht) and Khuzestan (Ezh, Ramhormoz and Ahodasht) provinces. Nitrate non-utilizing (Nit) mutants were generated on Czapeck media, containing $5 \% \mathrm{KClO}_{3}$. Phenotypic classes of nit mutants were determined to 17 different Vegetative Compatibility Groups (VCGs) on media containing nitrate, hypoxanthine and ammonium. The largest group contained 18 isolates and others contained two and one, respectively. 24 isolates were selected for RAPD test, to represent 17 vegetative compatibility groups. A set of seven random primers revealed a total of 36 alleles. High level of genetic diversity was observed among $F$. verticillioides isolated in the region. 29 alleles (80.55) showed high polymorphism in all the isolates. Genetic relatedness was calculated based on genetic distance matrix, and 11 groups were clustered based on UPGMA and Dice coefficient.
\end{abstract}

Keywords: Fusarium verticillioides; RAPD; Vegetative compatibility

\section{Introduction}

Rice (Oryza sativa L.) is one of the most important grains consumed by almost half of the world's population [1]. Root rot and crown rot are significant diseases of rice that yield the most losses in various ricegrowing areas [2]. Bakanae disease caused by Fusarium verticillioides (syn. F. moniliforme) was first described in Japan, and now is widely distributing in Asia. In addition, the disease has been reported to be on the rice tracts of European countries and America [3,4]. The typical symptoms are the abnormal elongation of seedling and the fungus which not only causes considerable damage on many plants, but also is parasitic on plants without the production of visible symptoms [2]. The pathogen has a wide host range and is widespread throughout the world. It's also known to cause stalk rot and leaf blight [5]. Knowledge of the genetic structure of the F. verticillioides population might be useful, in order to establish effective strategies for controlling the disease [6]. There are a number of techniques used to observe genetic variation among fungal pathogens. One of the techniques is VCG which is based on the ability of the mycelium to anastomose to form heterokaryon, for the aim of determining genetic relatedness [7]. The VCG technique is particularly suitable for population genetic studies of F. verticillioides, since the field isolates of this fungus belong to many VCGs [8]. Several molecular techniques are available for investigating genetic variability within plant pathogenic fungi population, such as Random Amplified Polymorphic DNA (RAPD) and Restriction Fragment Length Polymorphism (RFLP) [9]. Random Amplified Polymorphic DNA (RAPD) analysis has many advantages, as a means of characterizing genetic variability such as speed, low cost, and minimal requirement of DNA. RAPD markers are especially suitable for haploid plant pathogenic fungi, in which the dominance of amplified fragments does not affect genetic analysis [10]. This technique has been successfully used to assess genetic variability within many plant pathogenic fungi [11], including Fusarium section Liseola [12-14]. In this research, the characterization of $F$. verticillioides isolates (RAPD analysis and vegetative compatibility) and the relationship between pathogenicity and genetic markers, such as RAPD and vegetative compatibility group, are reported.

\section{Materials and Methods}

\section{Sampling, isolation, and the maintenance of fungal isolates}

Rice plant with brown and black symptoms on the root and crown were randomly collected during the growing seasons of 2009-2010, from different parts of rice-growing areas in Fars, a city in the southwest of Iran-namely Firozabad, Ramjerd, Drodzan, Shiraz, Pasargad, and Sepidan-and Khuzestan, located in the southeast of Iran-namely Ezeh, Ramhormoz and Ahodasht.

Diseased samples were cut into pieces of 2-5 mm, surface sterilized by dipping into domestic bleach solution (containing $1 \%$ of $\mathrm{NaOCl}$ ) for 2-3min, washed three times by sterile distilled water, dried by sterile filter paper, and finally plated on Potato Dextrose Agar (PDA) or Nash \& Snyder selective medium samples, which were incubated in an incubator at $23^{\circ} \mathrm{C}$ for 3 days. Isolates were seen to be single spored by harvesting conidia from a colony by a sterile needle, and through being streaked them on an agar plate containing $2 \%$ water. Conidia were incubated as above and single germinated conidia subcultured onto PDA plates and incubated with, for 2-3 weeks. Single-conidial isolates were stored on sterile filter paper at $20^{\circ} \mathrm{C}$. The identification of the fungal isolates was performed based on their morphological characteristic on Carnition-Leaf Agar (CLA) and PDA media. Afterwards, isolates were identified by Berges identification key internet [15].

*Corresponding author: Zeynab Bahmani, Department of Plant Pathology, Shahid Chamran University of Ahwaz-61357-831351, Iran, Tel: +989367214801; E-mail: z_bahmani65@yahoo.com

Received June 26, 2012; Accepted November 22, 2012; Published November 26, 2012

Citation: Bahmani Z, Nejad RF, Nourollahi K, Fayazi F, Mahinpo V (2012) Investigation of Fusarium verticillioides on the Basis of RAPD Analysis, and Vegetative Compatibility in Iran. J Plant Pathol Microbiol 3:147. doi:10.4172/2157-7471.1000147

Copyright: (c) 2012 Bahmani Z, et al. This is an open-access article distributed under the terms of the Creative Commons Attribution License, which permits unrestricted use, distribution, and reproduction in any medium, provided the original author and source are credited. 


\section{Vegetative compatibility}

Vegetative compatibility tests were conducted; following the protocols described by Puhalla [7] and Correll et al. [16]. Nitrate nonutilizing (nit) mutants were generated on Czapeck chlorate, containing $5 \% \mathrm{KClO}_{3}$ through using Potato dextrose agar+chlorate (PDC) medium containing various percents of chlorate, which were assigned to different physiological phenotypes (nit1, nitM, and nit3), on the basis of their growth on Minimal Medium (MM) amended with different nitrogen sources (nitrate medium, nitrite medium, hypoxanthine, and ammonium medium). Plates were incubated at $26^{\circ} \mathrm{C}$ in the dark.

\section{Complementation test and the determination of VCGs}

To identify vegetative self-incompatible isolates among all the rest, each nitM isolate was placed against nit1 or nit3 isolate and self-compatibility was observed by the dense growth (the formation of a heterokaryon), at the line of contact between the two mutants. Complementation was carried out between self-incompatible isolates, as described by Jacobson and Gordon [17]. NitM, each of the isolates was placed in the center and several blocks of nit1 and nit 3 from the same isolate were placed at the distance of $2 \mathrm{~cm}$ from the nitM block. The growth of aerial mycelium in confrontation between two colonies was an indicator of vegetative self compatibility [16]. Isolates that formed heterokaryons were assigned to the same Vegetative Compatibility Group (VCG).

\section{Fungal culture and DNA preparation}

Liquid culture was initiated by adding $5 \mathrm{~mm}$ mycelial discs from the growing edge of single conidial colonies grown on PDA to $250 \mathrm{~mm}$ Erlenmeyer flasks, containing $50 \mathrm{ml}$ of PDB (Potato Dextrose Broth) medium, and then were incubated at $28^{\circ} \mathrm{C}$ on an orbital shaker for two weeks. Mycelia from cultures were collected by vacuum filtration, washed by sterile distilled water, lyophilized, and finally ground in liquid nitrogen. Total genomic DNA was extracted from the powdered sample of mycelium, by using a modified Cetyl Trimethyl Ammonium Bromide (CTAB) procedure by Von Korf et al. [18]. The DNA was resuspended in $50 \mu \mathrm{l}$ of TE buffer and stored at $-20^{\circ} \mathrm{C}$.

\section{RAPD primer and amplification condition}

Seven arbitrarily chosen primers from Operon primer kit were tested for PCR amplifications of F. verticillioides DNA (Table 1). The preliminary amplification determined the optimal concentration of the component in the PCR reaction mixture. Amplifications were performed in a total volume of $25 \mu \mathrm{l}$ containing $2 \mu \mathrm{l}$ 10X PCR Buffer, $1.7 \mu \mathrm{l} \mathrm{MgCl}, 15 \mu \mathrm{l}$ water, $1 \mu \mathrm{l}$ primer, $2 \mu \mathrm{ldNTP}, 3 \mu \mathrm{l}$ template DNA, and $0.3 \mu \mathrm{ltag}$ polymerase. Each reaction was overlaid with one drop of mineral oil. The program included an initial denaturation at $94^{\circ} \mathrm{C}$ for $5 \mathrm{~min}, 45$ cycles with denaturation at $94^{\circ} \mathrm{C}$ for $2 \mathrm{~min}$, annealing $34^{\circ} \mathrm{C}$ for $1 \mathrm{~min}$, an extension step at $72^{\circ} \mathrm{C}$ for $2 \mathrm{~min}$, and a final extension at $72^{\circ} \mathrm{C}$ for $15 \mathrm{~min}$. Negative controls (no template DNA) were used for each set of experiments, to test for the presence of nonspecific

\begin{tabular}{|l|l|}
\hline Primer & Sequence \\
\hline OPA-516 & 5'-AGCGCCGACG -3' \\
\hline OPA-02 & 5'- TGCCGAGCTG-3' \\
\hline OPA-515 & 5'-GGGGGCCTCA-3' \\
\hline OPA-542 & 5'-CCCATGGCCC-3' \\
\hline OPA-548 & 5'- GTACATGGGC-3' \\
\hline OPA-540 & 5'- GCCCCTTTAC-3' \\
\hline OPA-07 & 5' - GGTCCCTGAC-3' \\
\hline
\end{tabular}

Table 1: Sequence of the primers used.

\begin{tabular}{|c|c|c|}
\hline Isolate & Location & VCG \\
\hline FK69 & Marvdasht & VCG1 \\
\hline FK78 & Ramjerd & VCG1 \\
\hline FK62 & Shiraz & VCG1 \\
\hline FK98 & Droodzan & VCG1 \\
\hline FK19 & Ramjerd & VCG1 \\
\hline FK17 & Ramjerd & VCG1 \\
\hline FK43 & Firozabad & VCG1 \\
\hline FK50 & Marvdasht & VCG1 \\
\hline FG17 & Ahodasht & VCG1 \\
\hline FK16 & Marvdasht & VCG1 \\
\hline FK63 & Marvdasht & VCG1 \\
\hline FK34 & Sepidan & VCG1 \\
\hline FG18 & Ezah & VCG1 \\
\hline FG3 & Ezah & VCG1 \\
\hline FG6 & Ahodasht & VCG1 \\
\hline FG22 & Ezah & VCG1 \\
\hline FG23 & Ezah & VCG1 \\
\hline FG24 & Ezah & VCG1 \\
\hline FK84 & Firozabad & VCG2 \\
\hline FK86 & Firozabad & VCG2 \\
\hline FG21 & Ezah & VCG3 \\
\hline FG19 & Ezah & VCG4 \\
\hline FK4 & Marvdasht & VCG5 \\
\hline FK80 & Droodzan & VCG6 \\
\hline FK37 & Pasargad & VCG7 \\
\hline FK114 & Marvdasht & VCG8 \\
\hline FK89 & Droodzan & VCG9 \\
\hline FK46 & Pasargad & VCG9 \\
\hline FK99 & Droodzan & VCG10 \\
\hline FK38 & Droodzan & VCG11 \\
\hline FK13 & Ramjerd & VCG11 \\
\hline FK42 & Firozabad & VCG12 \\
\hline FK104 & Marvdasht & VCG12 \\
\hline FK64 & Pasargad & VCG13 \\
\hline FK61 & Shiraz & VCG14 \\
\hline FK3 & Firozabad & VCG15 \\
\hline FK91 & Droodzan & VCG16 \\
\hline FK75 & Firozabad & VCG17 \\
\hline
\end{tabular}

Table 2: Location, Virulence and Vegetative compatibility group of isolates of Fusarium verticillioides.

reaction. The PCR products were electrophoresed on $1.2 \%$ of agarose, containing $3 \mu \mathrm{DNA}$, stained by ethidium bromide and visualized in a UV transilluminator.

\section{RAPD product scoring and data analysis}

Data were compiled as binary $0 / 1$ matrix by the presence (1) or the absence ( 0 ) of a band at a particular position. Only major RAPD bands were considered in statistical analysis. Dandrograms were produced by cluster analysis using the Unweighted Pair-Grouped Method by Arithmetic average (UPGMA), using the software Ntysys 2.01 version.

\section{Results}

\section{Identification}

The identification performed is based on the morphological characteristics. Aerial mycelium was white to pale orange or violet in almost half of the entire colony. Macroconidia observed on CLA, were slightly curved and septated. Microconidia were formed in chains ( 3 to 35 spores) on monophialides on $\mathrm{KCl}$ medium. Based on these 
mycological characteristics, 80 isolates were identified as Fusarium verticillioides.

\section{Vegetative compatibility group}

38 isolates were selected from a total of 80 of $F$. verticillioides, for the aim of VCG determination. No fast growing sector was produced, even after 14 days in Minimal medium cholorate (MMC) and PDC medium containing $1.5 \%$ and $3.5 \%$ of potassium chlorate. As a result, the concentration of $\mathrm{KClO}_{3}$ was increased to $6 \%$ and finally 41 nitrate nonutilizing mutants were obtained. The growth of many isolates was not limited. So, in order to increase efficiency, Czapeck chlorate containing $5 \%$ of $\mathrm{KClO}_{3}$ was used. In this medium, the production sectors were considerable. With this medium, 405 mutants were isolated in total. A total number of 446 mutants of $F$. verticillioides were obtained with $49.32 \%$ of nit $1,30.02 \%$ of nit 3 and $20.4 \%$ of nitM. Complementation among nit mutants was indicated by the development of the dense aerial growth, when the mycelia of the nit mutant colonies came in contact and anastomosed, to form a heterokaryon (Figure 1). All the isolates were grouped into 17 VCGs based on pairing complementary nit mutants, mainly with nit 3 and NitM. The largest one contained 18 , and the rest contained 1 or 2 members. These results indicated high genetic diversity caused by sexual reproduction.

\section{RAPD analysis}

Genetic variability among the 24 isolates from Khuzestan and Fars was assessed by RAPD analysis. In order to compare the overall

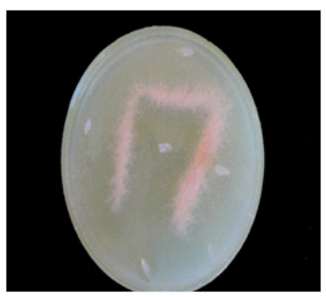

Figure 1: Heterokaryon growth on minimal medium

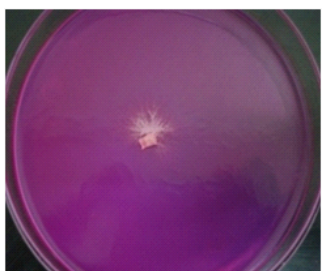

Figure 2: Sector production in Czapeck chlorate.

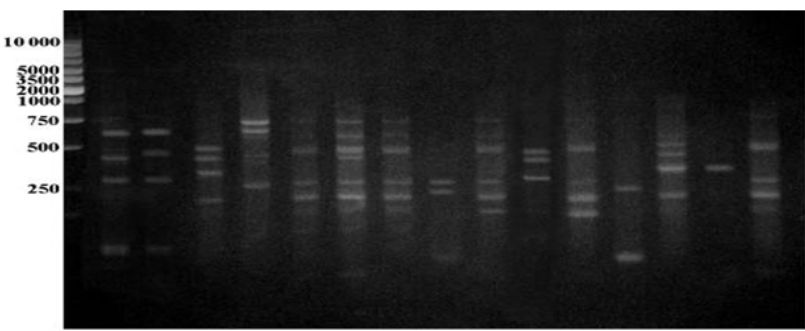

Figure 3: An example of amplification of genomic DNA using the Random amplified polymorphic DNA technique. Numbers represent different Fusarium verticillioides isolates. M, Molecular marker. similarity among these isolates at DNA level, 7 primers were used, which generated polymorphic bands (Figure 3). The data from polymorphic bands were analyzed by UPGMA. Among the seven primers, the most informative primer was OPA-2, which included 7 bands and it showed high polymorphism, while primer OPA-7 was low which had 3 fragments.

\section{Discussion}

The two goals of this study were to determine genetic diversity by VCG and RAPD techniques, and to assess the ability of RAPD, as compared to the VCG to genotype isolates of Fusarium verticillioides. VCG assignment was based on complementation reaction between NitM (or nit3) and nit1 mutants on minimal medium. In this investigation, there was no sector on MMC and PDC with $1.5 \%$ and $3 \%$ of potassium chlorate after 7-10 days, but MMC and PDC having $6 \%$ of potassium chlorate and 41 mutants were generated. To save time, Czapeck chlorate with $5 \%$ of chlorate was used, which increased the sector production. Jelodar [19] reached results similar to those of Czapeck medium. In her experiment, no sectors were produced in MMC medium with 1.5 and 3\% of chlorate, after 14 days. Sectors growth in MMC having 5\% of chlorate was limited, but most of isolates showed wild growth type, when they were transformed in minimal medium. Afterwards, she used Czapeck chlorate having 5\% of chlorate.

Different isolates of $F$. verticillioides were divided into 17 groups. The largest group was VCG1, including 18 members and other groups had 2 or 1 . No specific pattern was observed between geographical origin and VCG. The occurrence of isolates of different VCG in the same location indicates that there is considerable genetic diversity among these isolates.

RAPD analysis, a method widely used to characterize isolates, indicated a high level of genetic variability among isolates of fungi [20]. RAPD analysis was compared with the classification of pathogenicity groups through the use of 7 primes, but the results did not show good correlation between amplification patterns and pathotype classification.

Investigation on genetic diversity of F. oxysprum, using RAPD marker showed that the population of diseases had high genetic diversity. Also, the results showed that RAPD fingerprinting cannot provide, in most cases, the same resolution for genotyping as VCG. In most cases, RAPD divided a VCG into different haplotypes, while in other cases; a RAPD haplotype contained more than one VCG. It is, however, likely that greater resolution could have been obtained with RAPDs, by increasing the number of bands scored. In spite of the high sensitivity it did provide, the VCG technique alone for strain or clone identification would not be recommended. While VCG assays only one marker, RAPD analyses a number of markers that can be simply increased, in order for us to meet specific needs. The increase can be done by using primers. As a result, more detailed population genetic analyses can be conducted. In addition, the RAPD technique is more time- and labour- efficient than VCG typing. Isolates from two provinces were present in the same VCG, or the same RAPDs. This might be the result of gene flow between two provinces, or from a common gene pool of Fusarium isolates, that become established in the two provinces. The results indicate that there is high genetic variability among isolates of Fusarium verticillioides in two provinces, as identified by RAPD analysis that sexual reproduction can be one of the reasons [21]. In this study, the relationship between the VCG and RAPD results were very low; so that, only two isolates with the highest genetic similarity FG22 and FG17 were in same VCG and RAPD group. 
Citation: Bahmani Z, Nejad RF, Nourollahi K, Fayazi F, Mahinpo V (2012) Investigation of Fusarium verticillioides on the Basis of RAPD Analysis, and Vegetative Compatibility in Iran. J Plant Pathol Microbiol 3:147. doi:10.4172/2157-7471.1000147

Huang et al. [21] also found high genetic diversity among isolates of this pathogen in Israel; also they could find close relationship between VCG and RAPDs. But Zamani et al. [22], in their studies on the genetic diversity of Iranian isolates of $F$. oxysporum had no relation between results from RAPD and VCG test, too.

\section{References}

1. Cottyn B, Regalado E, Lanoot B, De Cleene M, Mew TW, et al. (2001) Bacterial populations associated with rice seed in the tropical enviroQment. Phytopathology 91: 282-292.

2. Saremi H, Ammarellou A, Marefat A, Okhovvat SM (2008) Binam a rice cultivar, resistant for root rot disease on rice caused by Fusarium moniliforme in Northwest, Iran. Int J Botany 4: 383-389.

3. Desjardins AE, Manandhar HK, Plattner RD, Manandhar GG, Poling SM, et al. (2000) Fusarium species from Nepalese rice and production of mycotoxins and gibberellic acid by selected species. Appl Environ Microbiol 66: 1020-1025.

4. Saremi H (2000) Plant disease caused by Fusarium species. ( $1^{\text {st }}$ edn), Jehad Daneshgahi Press University of Mashhad, Iran, 1145.

5. Booth C (1971) The Genus Fusarium. Kew, Commonwealth Mycological Institute, UK

6. McDonald BA (2004) Population genetics of plant pathogens. The Plant Health Instructor.

7. Puhalla JE (1985) Classification of strains of Fusarium oxysporum on the basis of vegetative compatibility. Can J Bot 63: 179-183.

8. Leslie JF, Doe FJ, Plattner RD, Shackelford DD, Jonz J (1992) Fumonisin B1 production and vegetative compatibility of strains from Gibberella fujikuro mating population 'A' (Fusarium moniliforme). Mycopathologia 117: 37-45.

9. Williams JG, Kubelik AR, Livak KJ, Rafalski JA, Tingey SV (1990) DNA Polymorphisms amplified by arbitrary primers are useful as genetic markers. Nucleic Acids Res 18: 6531-6535

10. Williams JGA, Kubelik AR, Rafalski JA, Tingey SV (1991) Genetic analysis with RAPD markers. In: Bennett JW, Lasure LL eds, More Gene Manipulations in Fungi, Academic Press, San Diego, CA, USA 431-439.

11. Jones MJ, Dunkle LD (1993) Analysis of Cochliobolus carbonum races by PCR amplification with arbitrary and gene- specific primers. Phytopathology 83: 366
12. Amoah BK, MacDonald MV, Nicholson P, Rezanoor HN (1995) Variation in the Fusarium section Liseola: pathogenicity and genetic studies of isolates of Fusarium moniliforme sheldon from different hosts in Ghana. Plant Pathol 44 536-572.

13. Voigt K, Schleier S, Bruckner B (1995) Genetic variability in Gibberella fujikuroi and some related species of the genus Fusarium based on Random Amplification of Polymorphic DNA (RAPD). Curr Genet 27: 528-535.

14. MacDonald MV, Chapman R (1997) The incidence of Fusarium moniliforme on maize from Central America, Africa and Asia during 1992-1995. Plant Pathol 46: 112-125.

15. Leslie JF, Summerell BA (2006) The Fusarium Laboratory Manual. Blackwell Publishing, USA

16. Correll JC, Klittich CJR, Leslie JF (1987) Nitrate nonutilizing mutants of Fusarium oxysporum and their use in vegetative compatibility tests. Phytopathology 77 : 1640-1646.

17. Jacobson DJ, Gordon TR (1988) Vegetative compatibility and self-incompatibility within Fusarium oxysporum f. sp. melonis. Phytopathology 78: 668-672.

18. Von Korff M, Udupa SM, Yahyaoui A, Baum M (2004) Genetic variation among Rhynchosporium secalis populations of West Asia and North Africa as revealed by RAPD and AFLP analysis. J Phytopathol 152: 106-113.

19. Jelodar A (2009) Isolation and identification Fusarium species associated with Corn and investigation of genetic diversity among dominant species population used vegetative compatibility groups in Khozestan province. Thesis of master of science plant diseases, Agriculture college, Shahid Chamran University Ahvaz, Iran, 158

20. Wang PH, Lo HS, Yeh Y (2001) Identification of Fusarium oxysporum cucumerinum and Fusarium oxysporum luffae by RAPD- generated DNA probes. Lett Appl Microbiol 33: 397-401.

21. Huang R, Galperin M, Levy Y, Perl-Treves R (1997) Genetic diversity of Fusarium moniliforme detected by vegetative compatibility groups and random amplified polymorphic DNA markers. Plant Pathol 46: 871-881.

22. Zamani MR, Motallebi M, Rostamian A (2004) Characterization of Iranian isolates of Fusarium oxysporum on the basis of RAPD analysis, virulence and vegetative compatibility. J Phytopathol 152: 449-453. 